\title{
Application of laser capture microdissection and proteomics in colon cancer
}

\author{
L C Lawrie, S Curran, H L McLeod, J E Fothergill, G I Murray
}

\begin{abstract}
Aims-Laser capture microdissection is a recent development that enables the isolation of specific cell types for subsequent molecular analysis. This study describes a method for obtaining proteome information from laser capture microdissected tissue using colon cancer as a model.

Methods-Laser capture microdissection was performed on toluidine blue stained frozen sections of colon cancer. Tumour cells were selectively microdissected. Conditions were established for solubilising proteins from laser microdissected samples and these proteins were separated by two dimensional gel electrophoresis. Individual protein spots were cut from the gel, characterised by mass spectrometry, and identified by database searching. These results were compared with protein expression patterns and mass spectroscopic data obtained from bulk tumour samples run in parallel.

Results-Proteins could be recovered from laser capture microdissected tissue in a form suitable for two dimensional gel electrophoresis. The solubilised proteins retained their expected electrophoretic mobility in two dimensional gels as compared with bulk samples, and mass spectrometric analysis was also unaffected.

Conclusion-A method for performing two dimensional gel electrophoresis and mass spectrometry using laser capture microdissected tissue has been developed. (F Clin Pathol: Mol Pathol 2001;54:253-258)
\end{abstract}

Keywords: colon cancer; electrophoresis; proteomics

Department of

Molecular and Cell

Biology, University of

Aberdeen, Foresterhill, Aberdeen, AB25 2ZD, UK

J E Fothergill

Department of

Pathology, University

of Aberdeen

L C Lawrie

S Curran

G I Murray

Department of

Medicine and

Therapeutics,

University of Aberdeen

H L McLeod

Correspondence to:

Dr Murray

g.i.murray@abdn.ac.uk

Accepted for publication 25 January 2001 the protein expression profile occurring during tumour development and progression, thus leading to the identification of new molecular markers and potential therapeutic targets.

The molecular analysis of tumours requires the isolation of specific populations of cells: the presence of contaminating cells within a sample remains a major obstacle to meaningful biological analysis. Laser capture microdissection (LCM) is a recently developed technique that permits the rapid and reliable procurement of a specific type of cell from a tissue section, in one step, under direct microscopic visualisation..$^{6-8} \mathrm{LCM}$ has been used to isolate specific types of cells both for DNA and RNA analysis. $^{8-10}$

In our study, we have investigated the feasibility of and determined the experimental conditions for using cells obtained by LCM for proteome analysis; the strategy used is outlined in fig 1. We used LCM to isolate colon cancer cells or normal colonic epithelial cells and we have shown that proteins solubilised from microdissected cells can be used for $2 \mathrm{D}$ gel electrophoresis and the proteins can be identified by mass spectrometry.

\section{Materials and methods}

TISSUE

Paired samples $(n=4)$ of colon cancer and normal colon were obtained from colectomy specimens excised for colon cancer. Experienced gastrointestinal pathologists (GIM, SC)

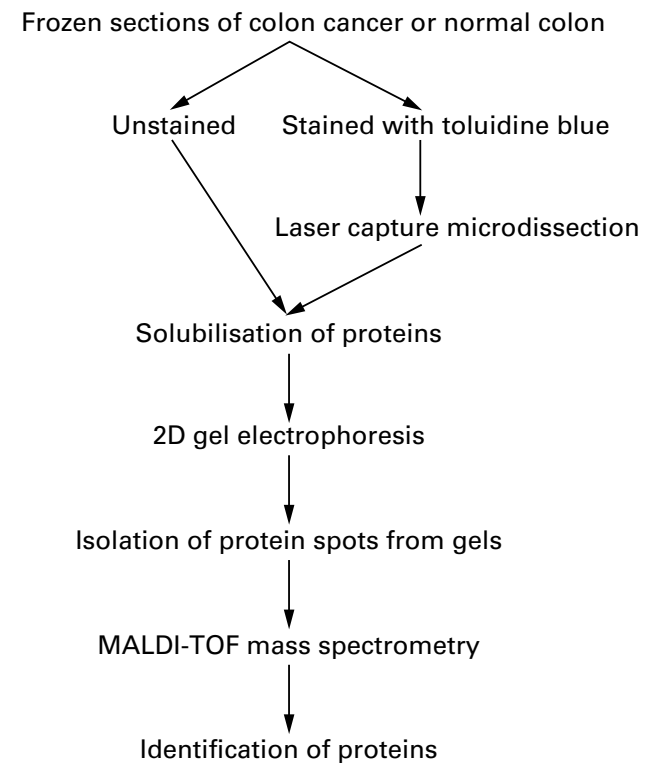

Figure 1 Outline of the strategy used to develop cell specific protein expression analysis integrating laser capture microdissection and proteome analysis. MALDI-TOF, matrix assisted laser desorption ionisation time of flight. 
dissected the colectomy specimens within 20 minutes of removal. Samples (approximately $10 \times 10 \times 5 \mathrm{~mm}$ ) of colon cancer were removed from viable tumour, avoiding obvious areas of necrosis, and macroscopically normal colonic mucosal samples were dissected from a distance of at least $10 \mathrm{~cm}$ from the tumour. Both the tumour and normal samples were then frozen in liquid nitrogen and stored at $-80^{\circ} \mathrm{C}$ until use.

\section{LASER CAPTURE MICRODISSECTION}

Frozen sections $(10 \mu \mathrm{m}$ thick) of either colon cancer or normal colonic mucosa were cut on a cryostat (Leica, Milton Keynes, Buckinghamshire, UK). Sections were thaw mounted on to clean uncoated glass slides, very briefly air dried (five seconds), and then fixed at room temperature in $70 \%$ ethanol for one minute. The sections were then stained with toluidine blue using a rapid staining method. Staining with toluidine blue was performed by immersing the sections in $0.25 \%$ toluidine blue $(\mathrm{pH} 4.5)$ for five seconds at room temperature, washing briefly in 100\% ethanol, and then dehydrating the sections sequentially in $100 \%$ ethanol and xylene. The xylene was allowed to evaporate completely from the sections and then the sections were microdissected using a PixCell II laser capture microdissection system (Arcturus Engineering, Mountain View, California, USA). The laser capture system was equipped with PixCell II image archiving software (Arcturus Engineering). Microdissection to obtain samples of either colon cancer cells or normal colon epithelial cells was performed by SC or GIM. The settings of the laser were as follows: spot diameter set at $15 \mu \mathrm{m}$, pulse duration 50 milliseconds, and power $50 \mathrm{~mW}$. Tissue was microdissected from eight to 10 sections of each sample with a separate "cap" being used to capture material from each section. Typically, 2500-3000 laser pulses were used for each cap. After microdissection, the plastic film containing the microdissected cells was removed from the rest of the cap, and all the films containing material from a single sample placed in a microcentrifuge tube and protein lysis solution added (see below). This modification of the recommended protocol for other applications for processing the caps ensured that small volumes of protein lysis solution could be used to obtain a sufficiently concentrated protein solution suitable for subsequent $2 \mathrm{D}$ gel electrophoresis. For comparison, to determine the effects of both histological processing and LCM on protein recovery, some frozen sections (whole tissue samples) were placed directly into microcentrifuge tubes followed by the addition of protein lysis solution, without the sections being subjected to either histological staining or LCM.

The protein concentration of LCM samples and whole tissue samples was determined using a Biorad DC protein assay kit (Biorad, Hemel Hempstead, Hertfordshire, UK). Parallel tissue samples were prepared in $0.01 \mathrm{M}$ ( $\mathrm{pH}$ 7.4) phosphate buffer in place of $2 \mathrm{D}$ protein lysis buffer because the protein assay is incompatible with the high concentration of urea present in this lysis solution.

2D GEL ELECTROPHORESIS

Unstained tissue sections were solubilised in 2D protein lysis buffer $(0.01 \mathrm{M}$ Tris $/ \mathrm{HCl}$,

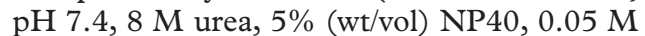
dithiothreitol (DTT), 6\% (wt/vol) $\mathrm{pH} 3-10$ ampholytes, $10 \%$ (vol/vol) glycerol). Samples prepared by LCM were disrupted in a modified lysis buffer (8 M urea, 4\% (wt/vol) CHAPS) and ultrasonicated in an ice bath to solubilise the proteins. The samples were stored at $-70^{\circ} \mathrm{C}$ until analysed by $2 \mathrm{D}$ gel electrophoresis. Protein samples were analysed on a small format $2 \mathrm{D}$ electrophoresis system. ${ }^{11}{ }^{12}$ The first dimension gels were $7 \mathrm{~cm} \mathrm{pH} \mathrm{3-10NL} \mathrm{immo-}$ bilised $\mathrm{pH}$ gradient (IPG) gels (Amersham Pharmacia Biotech, Little Chalfont, Buckinghamshire, UK), which were rehydrated overnight in a final volume of $125 \mu$ l rehydration buffer (8 M urea, 2\% CHAPS, 0.5\% IPG buffer, bromophenol blue, and DTT) containing the appropriate amount of sample. For LCM samples, 25-50 $\mu \mathrm{g}$ of protein was separated, whereas for bulk tissue samples $50-150 \mu \mathrm{g}$ of protein was used. The IPG gels were electrophoresed on a Multiphor II electrophoresis unit (Amersham Pharmacia Biotech), as described by the manufacturer under the following conditions: $200 \mathrm{~V}$ for one minute, $2500 \mathrm{~V}$ for 90 minutes, $3500 \mathrm{~V}$ for 65 minutes; the increase in voltage between these steps was achieved using a gradient ramp. After electrophoresis the gel strips were equilibrated in equilibration buffer $(50 \mathrm{mM}$ Tris/ $\mathrm{HCl}$, $\mathrm{pH}$ 6.8, $6 \mathrm{M}$ urea, 30\% (vol/vol) glycerol, $2 \%$ (wt/vol) sodium dodecyl sulphate (SDS)) containing 1\% (wt/vol) DTT for 30 minutes and then equilibration buffer containing $2.5 \%$ (wt/ vol) iodoacetamide for 30 minutes. The equilibrated strips were then laid on to the second dimension slab gels and the proteins separated on the basis of molecular mass on $7-15 \%$ gradient polyacrylamide gels in the presence of $0.1 \%$ (wt $/ \mathrm{vol}$ ) SDS. The proteins were separated at $100 \mathrm{~V}$ for 100 volthours and $200 \mathrm{~V}$ for an additional 300 volthours. The $2 \mathrm{D}$ gels were stained with silver (Amersham Pharmacia Biotech) or Coomassie brilliant blue G250. ${ }^{12}$ For every sample duplicate $2 \mathrm{D}$ gels were run. Digitised images of the gels were produced using a CCD camera (AstroCam, Cambridge, UK) for Coomassie blue stained gels or a Molecular Dynamics Personal Densitometer SI for silver stained gels.

IDENTIFICATION OF PROTEINS BY PEPTIDE MASS MAPPING

Protein spots were excised from Coomassie blue stained gels, washed, reduced in gel, $S$-alkylated, and digested in gel with trypsin (sequencing grade modified trypsin; Promega, Southampton, UK). ${ }^{13-15}$ An aliquot of the peptide extract produced by in gel cleavage was passed through a GELoader tip (Eppendorf, Hamburg, Germany), which contained a small volume of POROS R2 sorbent (PE Biosystems, Framingham, Massachusetts, USA), as described previously. ${ }^{13}$ The adsorbed peptides 
were washed extensively and then eluted in $0.5 \mu \mathrm{l}$ of a saturated solution of $\alpha$-cyano-4hydroxycinnamic acid (Sigma-Aldrich, Poole, Dorset, UK) in $75 \%$ acetonitrile $/ 5 \%$ formic acid. The mass spectra were acquired on a PerSeptive Biosystems Voyager-DE STR MALDI-TOF (matrix assisted laser desorption ionisation time of flight) mass spectrometer (PE Biosystems). The instrument was operated in the reflectron delayed extraction mode. Spectra were internally calibrated using trypsin autodigestion products. The masses of the tryptic fragments were entered into the MSFIT protein database searching program (http://prospector.ucsf.edu/ucsfhtml3.2/ msfit.htm). The MS-FIT program searches either the NCBI (National Center for Biotechnology Information) or SwissProt databases. The search parameters were as follows: cysteine as $S$-carbamidomethyl derivative; maximum allowed peptide mass error of 50 parts per million; more than five peptide mass hits required for a protein match. No restriction was placed on either the isoelectric point or species of origin of the protein. A protein mass range between 0 and $150 \mathrm{kDa}$ was allowed.

\section{Results}

The experimental factors that were found to be important to ensure satisfactory and consistent microdissection of cells using LCM were very brief air drying of sections on to uncoated glass slides and complete dehydration of sections after completion of the histological staining. Prolonged air drying of sections before staining appeared to inhibit successful LCM, and even trace amounts of moisture present in the sections appeared to inhibit, either partially or completely, the transfer of cells to the plastic film. Thus, complete dehydration of sections in xylene after histological staining was important. Colon cancer cells and normal colon epithelial cells were microdissected successfully from the tumour and normal sections, respectively (fig 2). The technique of LCM caused no visible alteration to the morphology of the dissected cells (fig 2 ).

Proteins could be solubilised from the cells captured by LCM in a form suitable for $2 \mathrm{D}$ gel electrophoresis (fig 3C and D). Tissue solubilised from 2500-3000 laser pulses contained approximately $1-5 \mu \mathrm{g}$ of total cellular protein. To achieve optimal solubilisation of proteins from LCM samples, a modified protein lysis solution omitting carrier ampholytes and DTT was used because it was found that the histological dyes interacted with both ampholytes and DTT.

Duplicate gels from each sample showed no significant variation in protein staining pattern. Proteins were selected for characterisation on the basis of their abundance and their separation from neighbouring protein spots. We obtained mass spectrometry data from all the protein spots cut from the gels. The characterisation of the proteins is summarised in tables 1 and 2 and figs 4 and 5. Cytokeratins 8 and 18 and $\beta$ actin were identified in LCM and unstained sections, and the peptide profiles were unaffected by LCM (fig 6 shows data for $\beta$ actin).

Comparison of the 2D gels prepared from unstained sections and those prepared from LCM samples showed a selective loss of non-epithelial (contaminating) proteins, most notably haemoglobin (fig 3; tables 1 and 2) after LCM. In addition, there was a greater representation in the LCM samples of intracellular epithelial structural proteins, including cytokeratins (fig 3; tables 1 and 2)

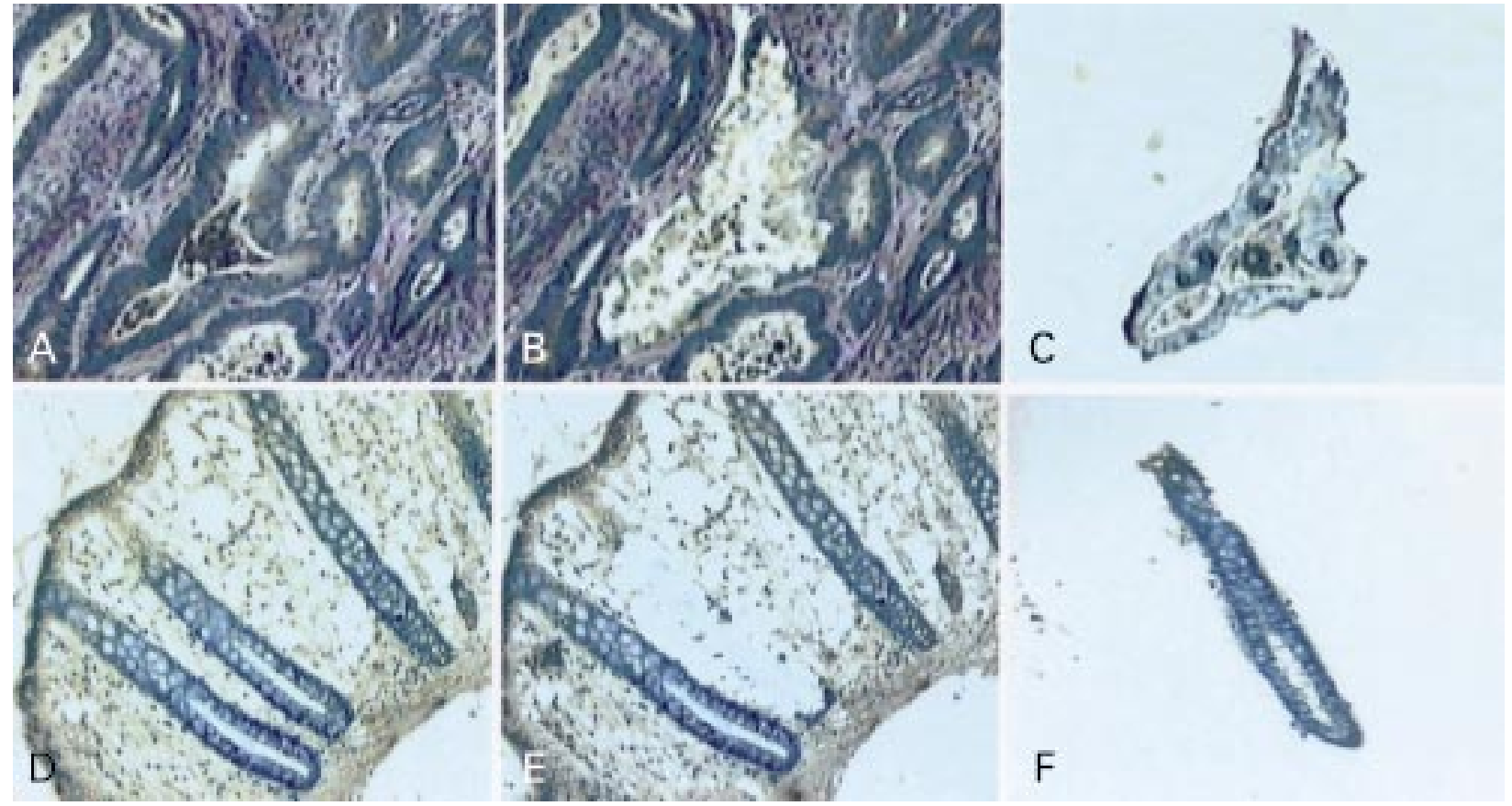

Figure 2 Photomicrographs of laser capture microdissection of toluidine blue stained sections of colon cancer ( $A-C)$ and normal colonic mucosa (D-F). Panels $A$ and $D$ show colon cancer and normal colon, respectively, before microdissection, whereas panels $B$ and $E$ indicate successful microdissection and panels $C$ and $F$ demonstrate successful capture and transfer of cells. 


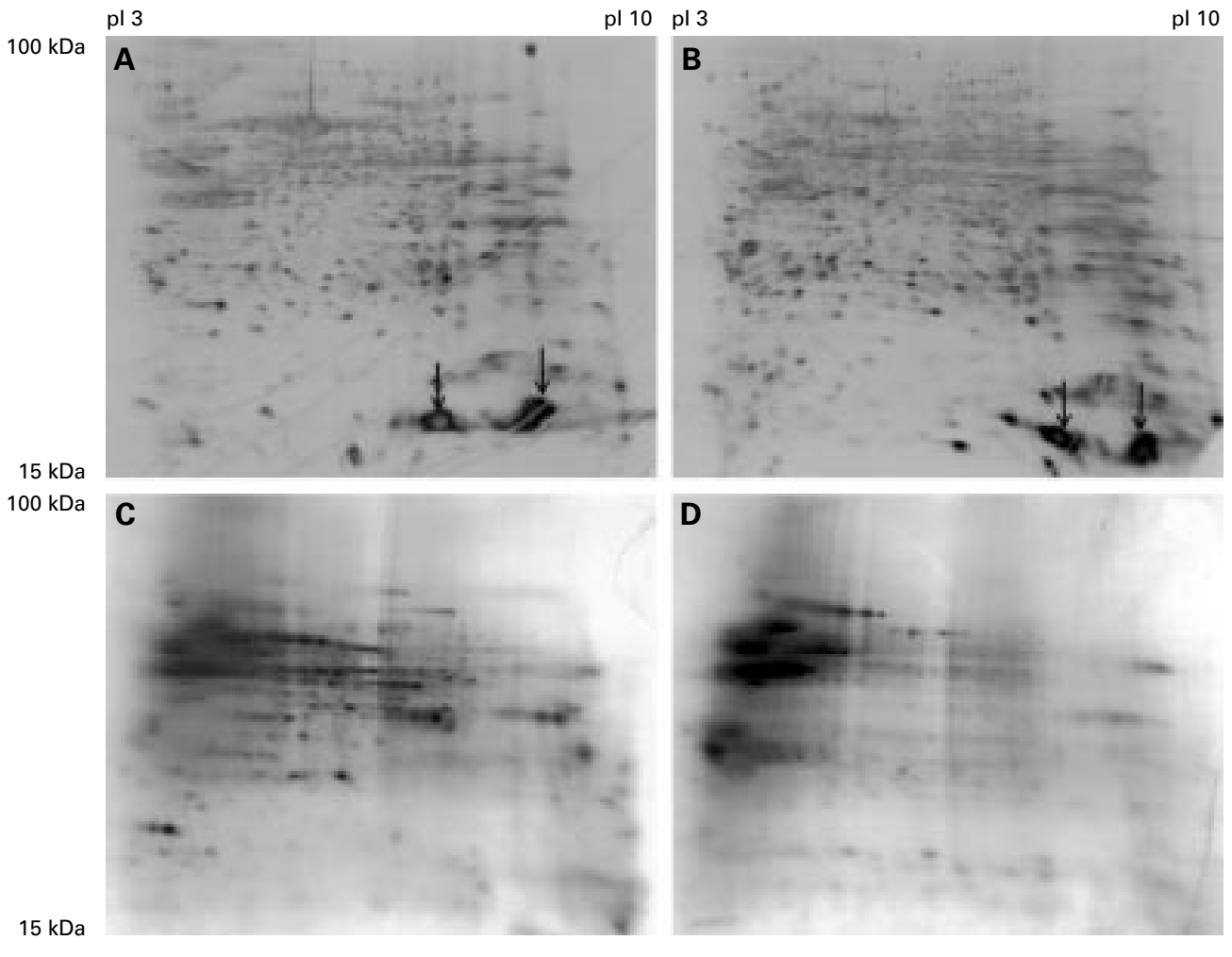

Figure 3 Two dimensional gels of normal colon and colon cancer. All the gels shown were prepared from tumour and normal samples obtained from the same patient. The first dimension separation was on non-linear IPG pH 3-10 gels with acidic proteins to the left of each gel. Proteins solubilised from frozen sections of $(A)$ normal colon mucosa and (B) colon cancer, which have not been subjected to laser capture microdissection (LCM) before two dimensional gel electrophoresis (Coomassie blue stained). Proteins solubilised from (C) normal colonic mucosa and (D) colon cancer, which have been subjected to LCM to isolate normal epithelial cells and tumour cells (silver stained). There is selective loss of individual contaminating proteins (especially haemoglobin identified by arrows in A and B) in LCM samples and a greater representation of intracellular structural proteins.

\section{Discussion}

The development of molecular analytical techniques and their application to the study of disease processes has been rapid in recent years. ${ }^{16}$ Although the technology has become increasingly sophisticated, the reliable interpretation of the results obtained is still largely influenced by the selection of appropriate study material in the first instance. Crucial to clinically relevant proteome analysis is the isolation of specific populations of cells from tissues, and this is particularly important in the analysis of tumours. LCM has made the acquisition of specific populations of cells from

Table 1 Identification of proteins from unstained samples of colon cancer by peptide mass mapping

\begin{tabular}{|c|c|c|c|}
\hline Spot no. & Protein description & $M W(D a)$ & $p I$ \\
\hline 1 & Cytokeratin 8 (fragment) & 53674 & 5.52 \\
\hline 2 & Cytokeratin 18 & 47926 & 5.34 \\
\hline 3 & $\beta$ Actin & 41737 & 5.29 \\
\hline 4 & $\alpha$ Enolase & 47169 & 7.01 \\
\hline 5 & Tropomyosin & 32990 & 4.63 \\
\hline 6 & $\beta$ Actin (fragment) & 41737 & 5.29 \\
\hline 7 & $27 \mathrm{kDa}$ heat shock protein & 22327 & 7.83 \\
\hline 8 & Thioredoxin peroxidase 1 & 21892 & 5.66 \\
\hline 9 & RNA binding protein & 19891 & 6.33 \\
\hline 10 & Nucleoside diphosphate kinase A & 17148 & 5.83 \\
\hline 11 & $\gamma$ Actin & 41793 & 5.31 \\
\hline 12,13 & Peptidylprolyl cis-trans isomerase A & 18012 & 7.68 \\
\hline $14-16$ & Haemoglobin $\beta$ chain & 15998 & 6.74 \\
\hline 17 & Cofilin & 18502 & 8.22 \\
\hline 18 & Haemoglobin $\alpha$ chain & 15257 & 8.72 \\
\hline
\end{tabular}

The numbers in the table correspond to the numbers in fig 4 .

The molecular weight (MW) in Daltons and pI values are for the predicted intact protein.
Table 2 Identification of proteins from a laser capture microdissection sample of colon cancer by peptide mass mapping

\begin{tabular}{llll}
\hline Spot no. & Protein description & MW (Da) & pI \\
\hline 1,2 & Cytokeratin 8 & 53674 & 5.52 \\
3 & B Actin & 41737 & 5.29 \\
4 & Cytokeratin 18 & 47926 & 5.34 \\
\hline
\end{tabular}

The numbers in the table correspond to the numbers in fig 5 . The molecular weight (MW) in Daltons and $\mathrm{pI}$ values are for the predicted intact protein.

tissues more straightforward because in comparison with other microdissection methods it permits the relatively rapid and efficient enrichment of selected populations of cells. ${ }^{6-8}$

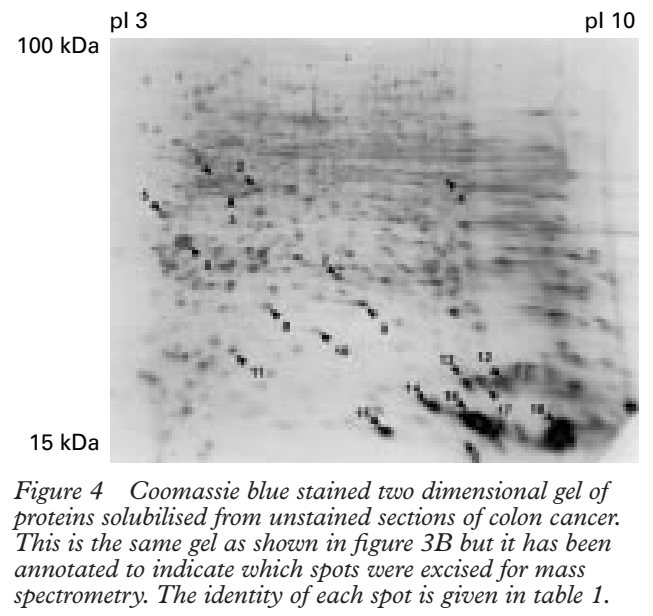




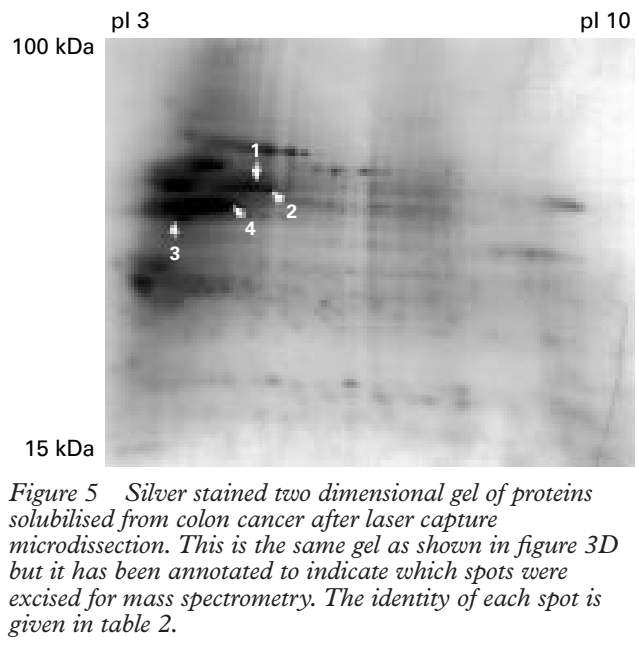

We have developed methods for combining the technologies of LCM and proteome analysis (2D gel electrophoresis and mass spectrometry). We have shown the feasibility of investigating protein expression in clinical samples using colon cancer as a model. We chose colon cancer because we have an ongoing programme of research into the biology of this
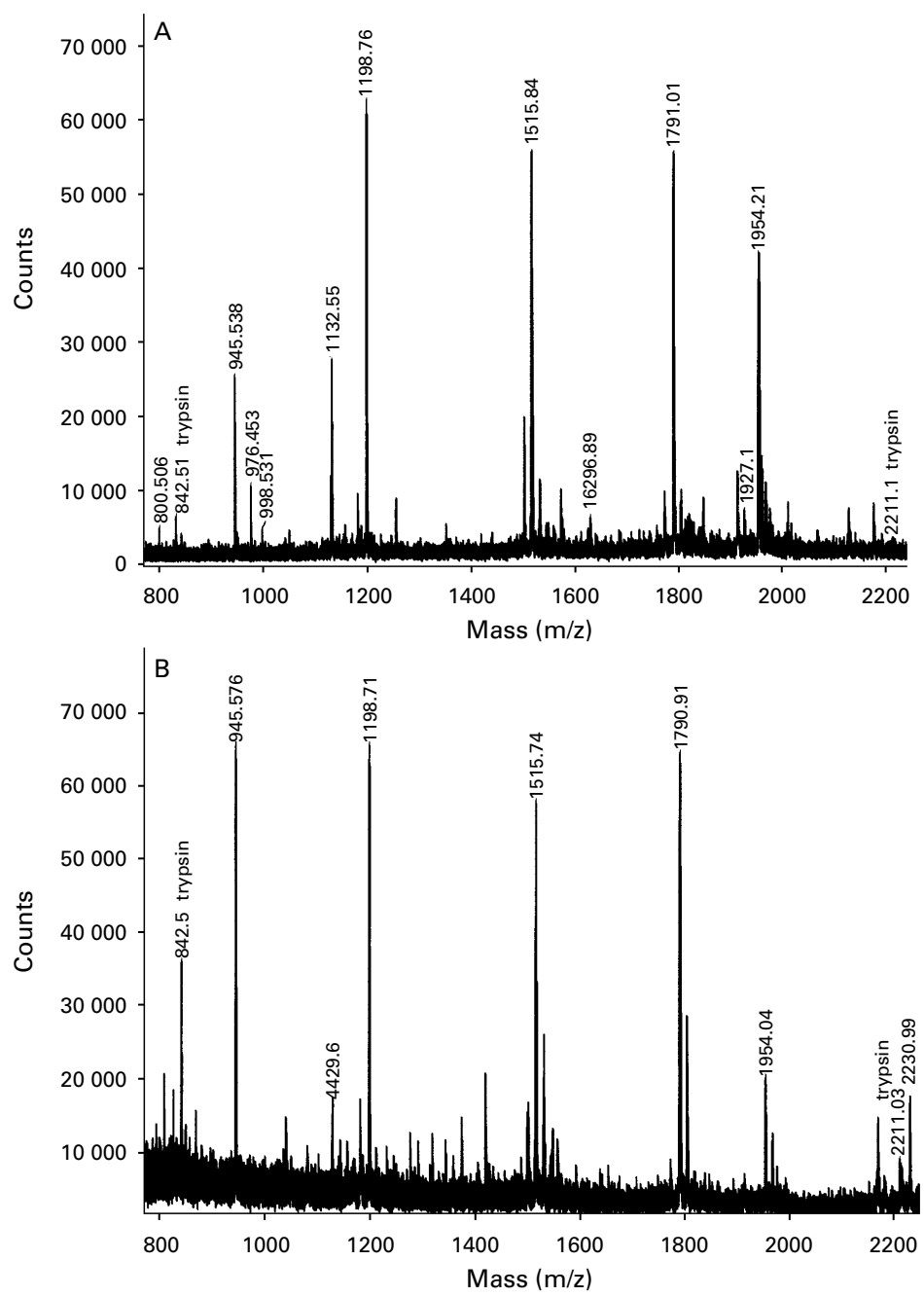

Figure 6 Mass spectrometry profiles of actin from $(A)$ unstained section of colon cancer and (B) colon cancer section after laser capture microdissection (LCM). The peptide mass profiles appear to be unaffected by LCM. tumour. Our study represents a systematic approach to investigating the factors involved in performing LCM, 2D gel electrophoresis, and peptide mass mapping. Although some preliminary findings using LCM and proteomics have been described recently using normal renal tissue, it was not clear which cell type was investigated because microdissection of whole glomeruli was illustrated. ${ }^{17}$

2D gel electrophoresis was performed on proteins solubilised from either colon cancer cells or normal colonic epithelial cells after LCM, and these results were compared with those from unstained frozen sections of colon cancer or normal colon, which contain a mixture of individual cell types. The ability to obtain mass spectrometry data from individual proteins appeared to be unaffected. The analysis of specific populations of cells separated by LCM resulted in selective loss of non-epithelial proteins, especially haemoglobin, and enrichment for intracellular epithelial proteins, especially structural proteins such as the cytokeratins, thus indicating that individual cell types had been obtained by LCM. The observed electrophoretic mobilities of the identified proteins isolated from LCM samples were consistent with their mobilities in gels from non-LCM samples. These latter findings are particularly important because the histological procedures used to prepare tissue for LCM involve alcohol fixation, staining with histological dye or dyes, and dehydration in organic solvents, all of which could potentially result in changes in the proteins. The use of toluidine blue as the histological stain ensured a very rapid one step staining method, thus minimising exposure to organic solvents that could alter protein structure.

A major problem encountered during proteomic analysis is contamination of the samples with keratin. The keratin originates from dust, hair, wool, and fingerprints and can completely overwhelm the signal obtained from the real sample, thereby preventing identification. If the samples are contaminated with human keratin then the database will predominantly identify cytokeratin 1, which was not found in our study. The identification of cytokeratins 8 and 18 is consistent with their known expression in colonic cancer cells. ${ }^{18}$

The combination of the technologies of LCM and proteomics will facilitate the systematic analysis of protein expression profiles in specific cell types in individual disease processes, and define changes in protein expression that occur with disease development and progression and the effects of treatment. However, further refinements of these technologies to permit the analysis of less abundant proteins and the analysis of smaller numbers of cells are required. ${ }^{19}$

LCL is in receipt of the Jean V Baxter Fellowship from the Scottish Hospital Endowments Research Trust. Research in the author's laboratories (GIM) is supported in part by an Aberdeen colorectal cancer initiative grant from the University of Aberdeen Development Trust. The PixCell II laser capture microscope was purchased by an equipment grant from the Faculty of Medicine and Medical Sciences University of Aberdeen. The proteome facilities were provided by a development
grant from the Scottish Higher Education Funding Council. 
The expert advice of Dr P Cash and the technical assistance of $\mathrm{L}$ Selway in performing the gel electrophoresis are acknowledged.

1 Anderson NL, Anderson NG. Proteome and proteomics: new new technologies, new conc

2 Chambers G, Lawrie L, Cash P, et al. Proteomics: a new approach to the study of disease. $\mathcal{F}$ Pathol 2000;192:280-8.
Blackstock WP, Weir MP. Proteomics: quantitative and Blackstock WP, Weir MP. Proteomics: quantitative and
physical mapping of cellular proteins. Trends Biotechnol physical mapping of cellular proteins. Trends Biotechno
1999;17:121-7.

4 Cash P. Proteomics in medical microbiology. Electrophoresis 2000;21:1187-201

5 Anderson L, Seilhamer J. A comparison of selected mRNA and protein abundances in human liver. Electrophoresis 1997; 18:533-7.

6 Emmert-Buck MR, Bonner RF, Smith PD, et al. Laser capture microdissection. Science 1996;274:998-1001.

7 Simone NL, Bonner RF, Gillespie JW, et al Laser capture: microdissection: opening the frontier to molecular analysis. Trends Genet 1998;14:272-6.

8 Curran S, McKay JA, McLeod HL, et al. Laser capture microscopy. $\mathcal{F}$ Clin Pathol: Mol Pathol 2000;53:64-8.

9 Fend F, Emmert-Buck MR, Chuaqui R, et al. Immuno-LCM: laser capture microdissection of immunostained frozen sections for mRNA analysis. Am f Pathol 1999;154:61-6.

10 Luo L, Salunga RC, Guo H, et al. Gene expression profiles of laser-captured adjacent neuronal subtypes. Nat Med 1999;5:117-22.
11 Cash P, Argo E, Bruce KD. Characterisation of Haemophilus influenzae proteins by 2-dimensional gel electrophoresis. Electrophoresis 1995;16:135-48.

12 Cash P, Argo E, Langford P, et al. Development of an Haemophilus 2D protein database. Electrophoresis 1997;18: 1472-82.

13 Wilm M, Shevchenko A, Houthaeve T, et al. Femtomole sequencing of proteins from polyacrylamide gels by nano-electrospray mass spectrometry. Nature 1996;379: 466-9.

14 Shevchenko A, Wilm M, Vorm O, et al. Mass spectrometric sequencing of proteins from silver stained polyacrylamide gels. Anal Chem 1996;68:850-8.

15 Ritchie H, Lawrie LC, Crombie PW, et al. Cross-linking of plasminogen activator 2 and $\alpha 2$-antiplasmin to fibrino(gen). J Biol Chem 2000;275:24915-20.

16 Caldas C. Molecular assessment of cancer. BMF 1998;316: 1360-3.

17 Banks RE, Dunn MJ, Forbes MA, et al. The potential use of laser capture microdissection to selectively obtain distinct populations of cells for proteomic analysis-preliminary findings. Electrophoresis 1999;20:689-700.

18 Leong AS-Y, Cooper K, Leong F JW-M. Manual of diagnostic antibodies for immunohistology. London: Greenwich Medical Media, 1999.

19 Corthals GL, Wasinger VC, Hochstrasser DF, et al. The dynamic range of protein expression: a challenge for proteomic research. Electrophoresis 2000;21:1104-15.

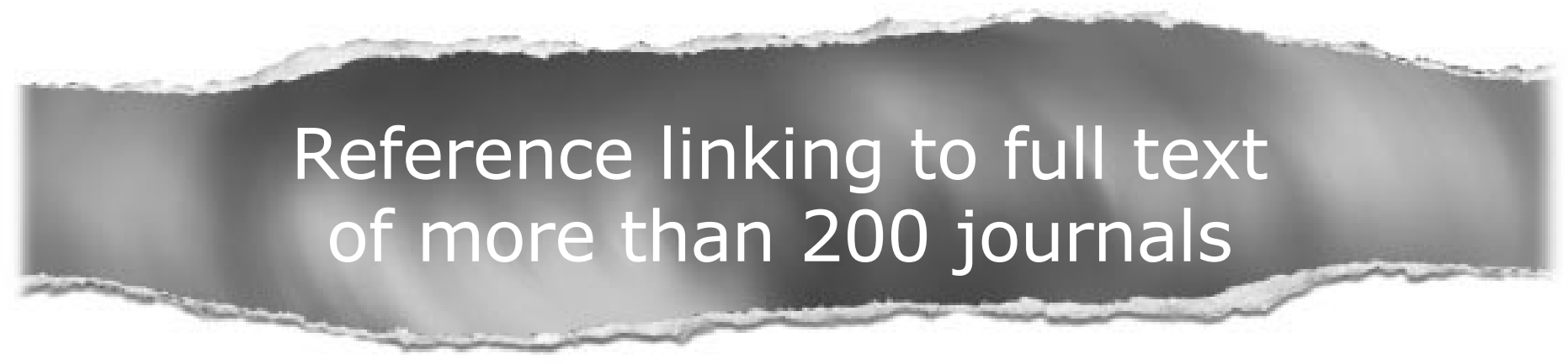

\section{Toll free links}

You can access the FULL TEXT of articles cited in the Journal of Clinical Pathology online if the citation is to one of the more than 200 journals hosted by HighWire (http://highwire.stanford.edu) without a subscription to that journal. There are also direct links from references to the Medline abstract for other titles.

www.jclinpath.com 